\title{
Effects Of Gender Presence In Senior Leadership Positions Upon Perspectives For Enhancing Workforce Diversity
}

James L. Morrison, University of Delaware, USA

G. Titi Oladunjoye, Albany State University, USA

Dale Rose, Ph.D. Student, Albany State University, USA

\begin{abstract}
The evidence gathered through this research supports the conclusion that the perceptions of leaders regarding who is more effective in addressing workforce diversity issues are more likely to be significantly different depending on the degree of presence of females' leaders in senior management. In this regard, the presence of female's leaders in senior management appears to be a significant factor in how males and females are perceived as to whom best allocates current operational resources when addressing workforce diversity issues
\end{abstract}

\section{INTRODUCTION}

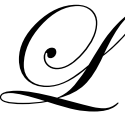
eaders of organization in the private sector are under considerable scrutiny by their boards of directors to achieve a diverse workforce because a homogenous workforce may be symptomatic of discrimination in the workforce. Because of this interest in developing a diverse workforce, there is also a growing curiosity as to how gender impacts upon addressing workforce diversity issues as they arise. The intent of boards of directors is to establish productive working environments that are also conducive to generating unity among employees with varying backgrounds. Therefore, the research question addressed here is, whether gender plays a significant role in the how diversity issues are being addressed in today's organizations.

In this study, leaders in senior management are those professionals at the highest level of organizational, such as the president, vice-president and chief financial officer. These are leaders who set the direction and establish the standards for others to follow for resolving issues related to workforce diversity. These are the individuals who set the tone by developing and establishing organizational policies for achieving workforce diversity with the goal of enhancing the efficiency and effectiveness of everyday operations

In this research, workforce diversity is defined as an organization of employees with differing characteristics, such as age, national origin, religion, disability sexual orientation, values, ethnic culture, education, language, lifestyle, beliefs, physical appearance and economic status (Went ling and Palma-Rivas, 2000). In this regard, diversity results in an organizational culture in which each employee can pursue his or her career aspirations without being inhibited by race, gender, nationality, and religion, etc. (Bryan, 1999). Therefore, a priority of today's leader is to put in place a strategy that results in a motivated workforce that consists of individuals who are capable of achieving their full potential without interference due to personal characteristics.

\section{SIGNIFICANCE OF WORKFORCE DIVERSITY AS AN ORGANIZATIONAL ISSUE}

Jhen (1999) points out that with increasing immigration and a corresponding increasing numbers of people working abroad, employees are now likely to face a multi-culture workforce. Today's organization is likely to consist of not only an increasing number of females but also more minorities, aging workers, disabled, and people with different lifestyles. To Wentling and Palma-Rivas (2000), the extent to which these individuals are effectively led will have an impact on the competitive ability of an organization, whether based in the USA or abroad. 
In this regard, Jackson (1991) argues that those leaders who recognize the globalization of labor as a positive trend and who acknowledge the significance attributed to an interdependency of their workforce will benefit the most. Fernandez (1998) reinforces this perception by suggesting that those leaders who fail to embrace cultural diversity will adversely affect worker productivity and customer satisfaction. Similarly, Fernandez also expresses the viewpoint that leaders must rethink their organization's mission, strategies, practices, markets, and products to meet the needs of an increasing diverse body of employees, customers, and other stakeholders.

\section{FEMALE PRESENCE IN SENIOR MANAGEMENT}

Subhash C. Kundu (2003) analyzed the reactions and perceptions of male and female employees about workforce diversity and concluded that male employees rated female employees as less qualified, less competent and less productive than females rated themselves. However, Kundu also noted that more women are gaining important work experience and education necessary to qualify for leadership positions. Stelter (2002) points out that organizations are subsequently being called upon to expand their perspective as to what constitutes effective leadership as it relates to gender and role expectations. This change in the number of females achieving a senior status in leadership positions is substantiated by the estimate that females will outnumber men in leadership roles by the year 2030. (Stelter, 2002).

According to Hayes (1999), in previous generations, women leaders were relatively few in number. There was an occasional female celebrity resulting from winning a beauty pageant, a civic leader particularly in lower levels of government, or head of a family corporation usually obtained via an inheritance. Women in these positions were considered an exception rather than a typical role model for other women. However, Hayes also points out that women today have a much more significant leadership presence. In the United States, we have women governors, senators, mayors, business owners, officers, and CEOs of corporations, university presidents, vice presidents, and deans. In other countries, there are women heads of state.

Men and women have long been believed to behave in different ways, and these differences have been a subject of interest for research (Clisbee, 2005). Due to these documented gender-based differences, researchers subsequently moved to examine the different ways that men and women lead. Men have been described as leading in a hierarchical, top down fashion, where power was defined as authority they have over others. Women, however, have been described as being collaborative leaders, relying on interpersonal relationships, where power was defined by their ability to bring people together and establish consensus (Clisbee, 2005).

\section{STATEMENT OF THE PROBLEM}

The focus of this research is upon determining if differences in the degree of presence of females in senior management positions (president, vice-president, chief financial officer, etc.) has a significant effect on an organization's approach to addressing workforce diversity issues in an organization in the private sector. In this regard, the two hypotheses tested are:

(1) The perceptions of male and female leaders in senior management as to organizational effectiveness for addressing workforce diversity issues will not vary by percentage of female leaders in senior management.

The perceived skill levels of male and female leaders in senior management as to effectiveness for addressing workforce diversity issues will not vary by percentage of females leaders in senior management.

\section{RESEARCH METHODOLOGY}

Data was gathered by means of a written survey instrument sent to 500 leaders in senior management. Theses leaders were randomly selected from a data published by LIST, Inc., which consisted of over 10,000 leaders. For this study, a leader in senior management is identified as those possessing the title of CEO, president, vicepresident, secretary, or chief financial officer of an organization. The survey was distributed by mail during the Fall 2006. 
The survey consisted of four parts. Part I requested information concerning the demographics of the respondents to the survey. Part II, consisting of 10 items, sought information regarding the workforce diversity environment. Respondents were requested to record their responses using a 5-point Likert-type scale with 5 indicating strong agree; and 1, strongly disagree. Part III had those in the sample respond to 15 practices that reflected alternatives for addressing workforce diversity issues. Part IV requested the participants to rate the skill level of both males and females for each of 15 strategies with a rating of 3 indicating neither gender was more adept than the other, a rating of 1 or 2 reflecting males more adept, and a rating of 4 or 5 reflecting a female more adept in applying that strategy. Data used in this research was gleamed from 139 responses to the written survey instrument, reflecting a rate of return of 27.8 percent.

An ANOVA (analysis of variance) statistical measure was performed on responses of females and males by percentage of females in senior management. In addition mean scores by percentage of females in senior management positions were computed for survey items reflecting the perceptions of both males and females in senior leadership positions.

\section{FINDINGS}

The sample of the study consisted of 83 males and 56 female leaders in senior management. In addition, 62 leaders were from organizations having 10 or less percent of females in senior management position; 32 from organizations with 11 to 20 percent, and 45, with those with 21 percent or higher. In addition, 22 leaders were from organizations with 100 or fewer employees, 58 from organizations with 101 and 1000, and 59 from organizations of over 1001 employees. Finally, in terms of title, 76 were CEOs or presidents, 25 vice-presidents and 38, secretary or treasurer.

Gender Presence of Leadership in Senior Management. The percentage of leaders in senior management by gender appears to be somewhat of a significant factor in the discrepancy of perceptions recorded on the written survey instrument. In terms of perceptions related to leadership dynamics within an organization, those leaders situated in organizations with at least 10 percent female leaders in senior management were significantly more in agreement that workforce diversity created lots of opportunities to share information and accountability was more apparent. Moreover, those leaders in organizations with less than 10 percent females in senior management were significantly more in agreement that there was a cultural bias in assessing job performance $(\mathrm{F}-4.15 ; \mathrm{p}<.05)$. (See Table 1) In terms of being accountable for addressing workforce diversity issues, those leaders in organizations that report a greater percentage of female leaders in senior management were significantly more in agreement attending to this responsibility (being held accountable) than leaders with fewer female leaders $(\mathrm{F}-5.10 ; \mathrm{p}<.05)$

Table 1

Comparison of Overall Perceptions of Leadership For Addressing Workforce Diversity Issues by Percentage Females in Senior Mgmt. Positions in Organization

\begin{tabular}{|c|c|c|c|c|c|}
\hline \multirow[b]{2}{*}{ Perception } & \multicolumn{3}{|c|}{ Mean Scores } & \multicolumn{2}{|c|}{ ANOVA** } \\
\hline & $\begin{array}{l}<10 \% \\
N=62\end{array}$ & $\begin{array}{l}11-20 \% \\
\mathrm{~N}=32\end{array}$ & $\begin{array}{c}21+ \\
\mathrm{N}=45\end{array}$ & $\mathrm{~F}$ & Prob. \\
\hline \multicolumn{6}{|l|}{$\begin{array}{l}\text { Leadership Dynamics-- } \\
\text { - }\end{array}$} \\
\hline Reflects Diversity of Customers & 3.19 & 3.34 & 3.20 & 0.50 & .608 \\
\hline Same Diversity Skills by Gender & 4.19 & 4.41 & 3.84 & 0.74 & .481 \\
\hline Assessment Based on Own Culture & 3.43 & 2.53 & 3.02 & 4.15 & $.018 *$ \\
\hline Accountability/Achieving Diversity Goals & 3.46 & 3.75 & 3.73 & 5.10 & $.007 *$ \\
\hline Create Oppt. to Share Information & 3.38 & 3.65 & 3.93 & 5.49 & $.005 *$ \\
\hline \multicolumn{6}{|l|}{ Organizational Support -- } \\
\hline Freq. Training Sessions on Diversity Issues & 3.06 & 3.56 & 3.26 & 0.36 & .698 \\
\hline Diversity Initiatives into Strategic Planning & 3.77 & 4.06 & 3.88 & 2.14 & .111 \\
\hline Enhancing a Future Diverse Leadership & 2.85 & 2.47 & 2.76 & 1.20 & .304 \\
\hline Maintaining Gender Diversity & 2.84 & 2.21 & 2.28 & 2.92 & $.051 *$ \\
\hline
\end{tabular}


In terms of organizational support, those leaders in organizations having more than 10 percent females in senior management were significantly more in disagreement as to capability of organization maintaining a balance of gender diversity in their leadership. ( $\mathrm{F}-2.92 ; \mathrm{p}<.05)$ In addition, leaders in all three levels of organizations similarly disagreed that their organizations were capable of enhancing a future diverse leadership by having existing set of new leaders waiting in the wings. (Means $-2.85<10$ percent female; 2.47 for between 11 and 20 percent female; and $2.76>20$ percent female). (See Table 1)

In terms of personal actions undertaken to enhance workforce diversity in their organizations, the percentage of female leaders in senior management appears not to play a significant role. In this regard, respondents irrespective of the percentage of females in leadership positions basically disagreed that workforce diversity inhibits the pace of their leading change within their organization, that it is more difficult for them to resolve diversity conflict than other kinds of conflict, and their actions are negatively impacted during their annual performance assessment. (See Table 2.) Those in organizations with 20 percent or less female leaders were significantly more in agreement that they can openly discuss diversity issues in their organization than those with large female presence $(\mathrm{F}-2.91 ; \mathrm{p}>.05)$.

However, in terms of organizational sensitivity to a variety of aspects to workforce diversity, there are considerable significant discrepancies in perceptions of leaders depending on the amount of presence of female leaders in that organization. In terms of their individual treatment in their organization, leaders in organizations where there was over 20 percent presence of female leaders were significantly more in agreement that they worked in a diversity friendly atmosphere $(F-3.04 ; p<.05)$ and that they were treated equally to those of the opposite gender $(F-2.40 ; p<.10)$ than organizations with fewer female leaders in senior management. (See Table 2.) However, in organizations with over 20 percent leaders who are female, there was a significant disagreement in perceptions from leaders in those organizations having less than 20 percent females to the statements that they felt isolated from senior management $(F-3.16 ; p<.05)$ and not being as far along as we think $(F-5.34 ; p<.05)$. Finally, those leaders in organizations with 20 percent of less females in senior management positions were more in agreement that leaders with diverse background must be more proactive themselves in order to advance in their careers $(\mathrm{F}-6.43 ; \mathrm{p}, .<.05)$.

Table 2

Comparison of Personal Sensitivity and Initiatives for Enhancing Workforce Diversity Effectiveness by Percentage of Females in Senior Mgmt. Positions in Organizations

\begin{tabular}{|c|c|c|c|c|c|}
\hline \multirow[b]{2}{*}{ Perception } & \multicolumn{4}{|c|}{ Mean Scores } & \multirow[b]{2}{*}{ Prob**. } \\
\hline & $<10 \%$ & $11-20 \%$ & $21+$ & $\mathrm{F}$ & \\
\hline \multicolumn{6}{|l|}{ Personal Actions to Enhance Diversity - } \\
\hline Openly Discuss Diversity Issues & 4.38 & 4.34 & 4.09 & 2.91 & $.052 *$ \\
\hline Participate in Diversity Training & 3.55 & 4.03 & 3.81 & 0.84 & .435 \\
\hline Inhibit Pace of Change & 1.74 & 1.78 & 1.75 & 0.77 & .465 \\
\hline Mentor Another From Different Culture & 3.51 & 3.53 & 3.24 & 0.35 & .703 \\
\hline No Relation to Annual Reviews & 2.09 & 1.81 & 2.09 & 2.02 & .137 \\
\hline Difficult to Resolve Diversity Conflict & 2.40 & 2.18 & 2.49 & 1.25 & .291 \\
\hline \multicolumn{6}{|l|}{ Personal Diversity Sensitivity - } \\
\hline Diversity Friendly Atmosphere & 4.05 & 4.09 & 4.27 & 3.04 & $.051 *$ \\
\hline Equal Treatment by Gender & 4.45 & 4.03 & 4.56 & 2.40 & $.095 *$ \\
\hline Treated Fairly by Ethnicity & 4.54 & 4.19 & 4.61 & 1.36 & .260 \\
\hline Isolated from Senior Management & 2.22 & 2.75 & 1.69 & 3.16 & $.046 *$ \\
\hline Not Far Along As We think & 3.19 & 3.44 & 2.86 & 5.34 & $.006 *$ \\
\hline Commonality of Issues & 3.29 & 3.65 & 3.22 & 1.67 & .193 \\
\hline Minimize Views to Fit Leadership Model & 2.74 & 3.59 & 2.18 & 2.81 & $.101 *$ \\
\hline Proactive in Career Direction & 3.82 & 4.01 & 3.27 & 6.43 & $.000 *$ \\
\hline
\end{tabular}

Note: ** One-Way Analysis of Variance * significance: >.10

Note: Rating Scale: 5 - strongly agree; 3- not certain; 1- strongly disagree 
In final terms of who is more adept in attending to workforce diversity issues, the percentage of females in leadership positions played a significant role in the perceptions in this regard. (Table III) In this regard, generally those leaders in organizations where there was 10 percent of more female leaders perceived female leaders as being significantly more adept in allocating resources to enhance multi- cultural inclusion during the workday $(\mathrm{F}-5.8 ; \mathrm{p}$ $<.05)$, building positive relationships $(\mathrm{F}-5.22 ; \mathrm{p}<.05)$, creating a prejudice-free environment $(\mathrm{F}-2.54 ; \mathrm{p}<.10)$, recruiting diverse workers $(\mathrm{F}-2.72 ; \mathrm{p}<.10)$, and fostering trust $(\mathrm{F}-7.323 ; \mathrm{p}<.05)$. Along this same order of thinking, those leaders in organizations with over 20 percent female leaders in senior management had significantly less degree of agreement that female leaders were more effective in allocating resources to resolve diversity issues $(F-9.29 ; p<.05)$, being more cultural sensitive $((f-9.13 ; p<.05)$, and tolerating difference $(\mathrm{F}-7.72 ; \mathrm{p}<.05)$. However, females in organizations having over 20 percent female leaders in senior management disagreed that females were more adept in bringing about change ( $\mathrm{F}-5.02 ; \mathrm{p}<.05)$ whereas those leaders with a lesser (less than 20 percent female leaders) presence of females indicated females were more adept at this task.

Table3

Comparison of Degree of Skill to Leverage Resources for Attending Workforce Diversity Effectiveness by Percentage of Females in Senior Mgmt. Positions in Organization

\begin{tabular}{lllllll}
\hline & \multicolumn{3}{c}{ Mean Scores } & \multicolumn{3}{c}{ Prob. } \\
\hline Perception & $<10 \%$ & $11-20 \%$ & $21+$ & F & & \\
\hline Most Adept in Utilizing Following Means: & & & & & \\
Mentoring Diverse Workforce & 3.42 & 3.53 & 3.56 & 0.60 & .552 \\
Coaching Teams & 3.54 & 3.97 & 3.64 & 1.09 & .340 \\
Enhancing Inclusion & $\mathbf{3 . 7 4}$ & $\mathbf{4 . 1 9}$ & $\mathbf{3 . 8 2}$ & $\mathbf{5 . 1 8}$ & $\mathbf{. 0 0 7}^{*}$ \\
Relationship-Building & $\mathbf{3 . 7 6}$ & $\mathbf{4 . 0 6}$ & $\mathbf{3 . 7 3}$ & $\mathbf{5 . 2 2}$ & $\mathbf{. 0 0 6}^{*}$ \\
Bringing About Change & $\mathbf{3 . 4 2}$ & $\mathbf{3 . 6 9}$ & $\mathbf{2 . 8 6}$ & $\mathbf{5 . 0 2}$ & $\mathbf{. 0 0 8}^{*}$ \\
Creating Prejudice-Free Environment & $\mathbf{3 . 3 5}$ & $\mathbf{3 . 8 1}$ & $\mathbf{3 . 2 1}$ & $\mathbf{2 . 5 4}$ & $\mathbf{. 0 8 3}^{*}$ \\
Having Positive Disposition & 3.30 & 3.28 & 3.41 & 1.34 & .266 \\
Recruiting Diverse Workers & $\mathbf{3 . 2 5}$ & $\mathbf{3 . 5 9}$ & $\mathbf{3 . 2 4}$ & $\mathbf{2 . 7 2}$ & $\mathbf{. 0 7 0}$ \\
Collaborating Across Cultures & 3.30 & 3.78 & 3.24 & 1.01 & .367 \\
Finding Common Ground & 3.35 & 3.78 & 3.40 & 0.07 & .786 \\
Fostering Trust & $\mathbf{3 . 2 5}$ & $\mathbf{3 . 3 7}$ & $\mathbf{3 . 4 2}$ & $\mathbf{7 . 3 2}$ & $\mathbf{. 0 0 0}^{*}$ \\
Resolving Diversity Issues & $\mathbf{3 . 5 1}$ & $\mathbf{4 . 1 1}$ & $\mathbf{3 . 3 1}$ & $\mathbf{9 . 2 9}$ & $\mathbf{. 0 0 0}^{*}$ \\
Being Cultural Sensitive & $\mathbf{3 . 5 6}$ & $\mathbf{3 . 7 1}$ & $\mathbf{3 . 1 5}$ & $\mathbf{9 . 1 3}$ & $\mathbf{. 0 0 0}^{*}$ \\
Tolerating Differences & $\mathbf{3 . 5 6}$ & $\mathbf{3 . 9 1}$ & $\mathbf{3 . 0 7}$ & $\mathbf{7 . 7 2}$ & $\mathbf{. 0 0 0}^{*}$ \\
\hline
\end{tabular}

Note: ** One-Way Analysis of Variance * *ignificance: $>10$

Note: Rating Scale: 5 - Female Greatly More Adept; 3-neither; 1-Male Greatly More Adept

\section{CONCLUSIONS}

Based on the findings of this research, it may be concluded that the percentage (or presence) of female leaders in senior management positions in organizations was a significant factor in the discrepancies among perceptions of leaders in regards to addressing a variety of workforce diversity issues. Leaders generally in organizations with a larger presence of female leaders were either significantly more in agreement or disagreement than their counterparts in organizations where females were of lesser presence.

In regards to who is more adept in dealing with the dimensions related to workforce diversity issues, it may be concluded that there were significant discrepancies among leaders in organizations, depending on the amount of female presence in senior management positions in organizations than in the private sector. Therefore, the hypothesis that the perceptions as to organizational effectiveness for addressing workforce diversity issues will not vary by percentage of female leaders in senior management was rejected. Similarly, the hypothesis that the skill levels of leaders in senior management for addressing workforce diversity issues will not vary by percentage of female leader in senior management was also rejected.

Therefore, the evidence gathered through this research supports the conclusion that the perceptions of leaders regarding who is more effective in addressing workforce diversity issues are more likely to be significantly 
different depending on the degree of presence of female leaders in senior management. In this regard, the presence of females' leaders in senior management appears to be a significant factor in how males and females are perceived as to who best allocates current operational resources when addressing workforce diversity issues. The greater the presence of female leaders in an organization, the more impact there is upon the perceptions of leaders as to who is more skillful. However, the less the female presence in positions in senior level leadership, the more likely females are seen as being more adept than males.

\section{REFERENCES}

1. Bryan, J. H. (1999). The diversity imperative. Executive Excellence, p. 6.

2. Clisbee, M. A. (2005). Gender differences in leadership Style: A literature analysis. Journal of Women in Education Leadership, p. 12-16.

3. Fernandez, J. P. (1998) Slaying the diversity dinosaur. Executive Excellence, p. 15.

4. Jackson, B. W. (et. al.) Diversity. Human Resource Management. Vol. 31, No. 1; p. 21-34.

5. Management Data Systems. Vol. 99, No. 3, p. 109-14.

6. Hayes, A. (1999). New presence of women leaders. Journal of Leadership Studies. Vol. 5, p. 23.

7. Jhen, K. (1999). Why differences make a difference: A field study on diversity, conflict and performance in workgroups. Administrative Science Quarterly, Vol.44, p. 14-17.

8. Kundu, S. Workforce diversity status, a study of employee's reactions (Emeral website, http://www.emeraldinsight.com) 17 pp. (also formerly published in Industrial Management and Data Systems, 1903, 4: 2003; p. 215-226)

9. Stelter, N. (2002). Gender differences in leadership: Current social issues and future organizational implications. Journal of Leadership Studies, Vol. 8, p. 31.

10. Wentling, R. M. Palma-Rivas, N. (2000) Current status of diversity initiative in selected multinational corporations, Human Resource Development Quarterly, Vo. 1 11, No. 1, p. 35-60. 